60-61| 2018

La culture dans l'enseignement du français langue étrangère: conceptions théoriques, programmes et manuels auX $\mathrm{XIX}^{\mathrm{e}}$ et $\mathrm{XX}^{\mathrm{e}}$ siècles

\title{
La culture en question dans l'enseignement du français au Portugal
}

Culture in question in the teaching of French in Portugal

\section{Ana Clara Santos}

\section{OpenEdition \\ Journals}

Édition électronique

URL : https://journals.openedition.org/dhfles/5473

DOI : 10.4000/dhfles.5473

ISSN : 2221-4038

Éditeur

Société Internationale pour l'Histoire du Français Langue Étrangère ou Seconde

Édition imprimée

Date de publication : 1 janvier 2018

Pagination : 245-260

ISSN : 0992-7654

Référence électronique

Ana Clara Santos, «La culture en question dans l'enseignement du français au Portugal », Documents pour l'histoire du français langue étrangère ou seconde [En ligne], 60-61 | 2018, mis en ligne le 01 juin 2019, consulté le 25 mars 2023. URL : http://journals.openedition.org/dhfles/5473 ; DOI : https:// doi.org/10.4000/dhfles. 5473

Ce document a été généré automatiquement le 25 mars 2023.

Tous droits réservés 


\title{
La culture en question dans l'enseignement du français au Portugal
}

\author{
Culture in question in the teaching of French in Portugal
}

\author{
Ana Clara Santos
}

Si la langue latine, imposée par l'invasion et la force, a été l'idiome de la religion qui succédait à l'ancien monde, la langue française, propagée par la politique et les lettres, est et doit demeurer l'idiome principal de la civilisation qui réunit le monde moderne [...] elle ne saurait être désormais étrangère à aucun homme civilisé (Villemain 1835 : vii)

\section{Définitions et enjeux}

1 La notion de culture est elle-même polysémique. Aussi bien le Dictionnaire de l'Académie française que le Dictionnaire Littré l'associent comme sens premier au «travail de la terre » pour rendre celle-ci "plus fertile». C'est seulement dans un sens figuré, par extension, qu'elle devient « la culture des lettres, des sciences, des beaux-arts » afin de «travailler à la culture de l'esprit». Par contre, le Dictionnaire Larousse la désigne comme l'« ensemble des phénomènes matériels et idéologiques qui caractérisent un groupe ethnique ou une nation, une civilisation, par opposition à un autre groupe ou à une autre nation ». C'est cette acception du mot culture qui nous occupera ici puisqu'il s'agit de mesurer les transferts des «phénomènes culturels » français vers la culture portugaise, plus particulièrement en matière éducative.

2 Vouloir cerner ici, tant soit peu, le rôle de la langue et de la culture françaises à l'étranger, notamment dans le pays le plus au sud de l'Europe, le Portugal, nous oblige à interroger certains concepts, y compris celui d'« expansion linguistique ». Jean-Marie Klinkenberg, en définissant ce concept comme « le processus par lequel une variété de langue est amenée à élargir le champ de ses fonctions sociales", ne manque pas d'identifier sa "dimension spatiale », c'est-à-dire son déplacement géographique, 
comme l'une des plus spectaculaires (Klinkenberg 2008:9). Or, de notre point de vue, on insiste souvent sur les raisons d'ordre linguistique, économique et/ou politique de ce phénomène au détriment de sa dimension imagologique et pédagogique. Ainsi, proposons-nous dans cette étude de renverser l'angle d'optique et d'interroger les enjeux d'une certaine pratique culturelle nationale qui intègre volontairement les représentations de l'étranger, en l'occurrence celles de la France et de la culture française, pour en faire la base de la légitimation de nouvelles formes de circulation de biens symboliques (Bourdieu 1971) et de leur scolarisation.

\section{Éclosion d'une nouvelle culture}

Quelle était l'image de la langue et de la culture françaises en Europe du sud à partir du XVIII siècle ? Comme l'a si bien démontré Claude Hagège, nous sommes autorisés à parler de "rayonnement du français» (Hagège 2006) puisque celui-ci, rattaché aux classes sociales privilégiées, jouit, contrairement à l'anglais, de l'image d'une langue de l'élite :

En d'autres termes, son image était déjà, et depuis longtemps, celle d'une image des élites et des classes favorisées par la fortune. L'anglais, en revanche, était tout à fait libre de cette connotation, dans la mesure même où sa vocation populaire se nourrissait d'un fait essentiel : il avait été en Angleterre, durant tout le règne de la monarchie normande, l'idiome des masses, ce qui avait dès longtemps dessiné sa vocation de langue sans lien direct ni nécessaire avec la haute société. (Hagège $2006: 20)$

4 À cela s'ajoute le mythe de l'universalité du français forgé à Berlin quelques années avant l'éclosion de la Révolution française. Le concours de l'Académie de Berlin, en 1784, osait poser frontalement la question à l'étranger : « Qu'est-ce qui fait de la langue française la langue universelle en Europe?». Il est intéressant de noter que deux lauréats prêchent cette suprématie par des voies complémentaires à l'Académie allemande, Johann Christopher Schwab, Allemand, et Antoine Rivarol, fils d'émigrés piémontais. Johann Christopher Schwab ne croit pas à la perte de son statut faute de concurrence. De son point de vue, pour que la langue française perde sa suprématie et son statut de langue universelle, «il faudrait ou qu'elle vînt à s'altérer, ou que la culture d'esprit fût négligée dans la nation qui la parle, ou que cette nation perdît de son influence politique, ou que sous ces trois rapports une nation voisine reçût un accroissement proportionnel $»^{1}$ (Düwell, 1996 : 43). Antoine Rivarol clamait dans son «Discours sur l'universalité de la langue française » les acquis d'une suprématie qui lui advenait de sa clarté, sa rigueur et son élégance depuis sa projection à la cour du Roi Soleil :

Si nous avions les littératures de tous les peuples passés, comme nous avons celle des Grecs et des Romains, ne faudrait-il pas que tant de langues se réfugiassent dans une seule par la traduction? Ce sera vraisemblablement le sort des langues modernes, et la nôtre leur offre un port dans le naufrage. L'Europe présente une république fédérative composée d'empires et de royaumes, et la plus redoutable qui ait jamais existé. On ne peut en prévoir la fin, et cependant la langue française doit encore lui survivre. Les États se renverseront, et notre langue sera toujours retenue dans la tempête par deux ancres, sa littérature et sa clarté, jusqu'au moment où, par une de ces grandes révolutions qui remettent les choses à leur premier point, la Nature vienne renouveler ses traités avec un autre genre humain. (Rivarol 1784 : 58) 
Cette idée est reprise en France à plusieurs endroits. Citons ici seulement le cas assez flagrant de cette réalité culturelle illustrée dans l'avertissement de toutes les éditions du Dictionnaire universel de la langue française de Boiste (1803 : vii) : « Mon but est [...] de contribuer à ce que la langue française, conservée dans sa pureté, ne puisse pas cesser d'être, en Europe, LA LANGUE UNIVERSELLE ». Force est de reconnaître que cette idée d'universalité vient renforcer celle de génie de la langue et de la culture françaises et accentuer d'emblée le prestige lié à la circulation des œuvres écrites dans cet idiome ou tout bien symbolique exporté à l'extérieur de la France.

On le voit, la projection internationale du français est indissociable du rayonnement culturel qu'il renferme par la transmission de valeurs et d'idées de la Nation française. Ce processus, déclenché à l'étranger, surtout en territoire européen, au cours de la première moitié du XVIII ${ }^{e}$ siècle, s'accentue pendant le siècle suivant. La Péninsule ibérique ne fait pas exception et en fut bénéficiaire.

7 Si la culture française se voyait vulgarisée au XVIII ${ }^{\mathrm{e}}$ siècle auprès de l'élite portugaise, elle finissait néanmoins par être un peu ébranlée sous le mécanisme répressif de la censure et de l'instabilité politique. Il a fallu attendre le siècle suivant pour assister à l'éclosion de la légitimation de la culture française dans le panorama culturel portugais. La révolution romantique, entamée dans le champ littéraire après 1834, à la fin des luttes libérales (entre constitutionalistes et absolutistes), ouvrait les portes vers de profonds débats idéologiques et des réformes structurantes dans le secteur culturel et éducatif ; l'éducation des masses et l'accès à la connaissance scientifique et artistique étant des axes prioritaires. La presse dans sa variété, aussi bien celle à vocation universaliste que celle qui se voulait spécialisée en littérature, en théâtre ou en pédagogie, établissait des ponts entre la culture étrangère (majoritairement française) et la culture nationale. La presse, par la mise à l'ordre du jour des nouvelles tendances esthétiques ou idéologiques, contribuait au rapprochement culturel entre Lisbonne et Paris par l'instauration, dans la capitale portugaise, d'un nouveau goût à la française.

8 Les phénomènes de gallomanie et de francophilie abondent à cette époque dans le domaine culturel. Il n'est donc pas étonnant de constater que, du point de vue socioculturel, Lisbonne s'habille à la française, dans le sens littéral du mot; mais aussi dans le secteur littéraire et artistique, grâce aux modèles importés, en langue originale ou en traduction, voués à être lus, imités, édités ou joués dans les salles de spectacle de la capitale. Au théâtre, on est surtout avide des nouveautés du théâtre de boulevard qui sont jouées par des troupes françaises (et adaptées, par la suite, au goût national par les troupes portugaises); en littérature et dans le monde éditorial, on s'inspire et on imite les mouvements innovateurs qui soufflent de Paris, le romantisme et le réalisme, mais on n'oublie pas le culte des auteurs classiques promus par les générations du siècle précédent ainsi que les grands philosophes des Lumières autrefois censurés et interdits. Petit à petit, par ce phénomène d'importation et du maintien de ce contact privilégié avec l'Autre, ce sont les goûts et les mœurs qui changent. La langue et la culture françaises jouissent alors d'un prestige et d'une légitimité immenses : jouer du piano et parler français est alors synonyme de bonne éducation féminine ; connaître les grands auteurs français à l'école était synonyme de reconnaissance sociale. C'est ainsi que Eça de Queirós, le chef de file de l'école réaliste portugaise, trace, dans cet extrait écrit à la fin du XIX ${ }^{e}$ siècle dans lequel il fait le tour de la création littéraire et théâtrale, des programmes scolaires et de la mode, une belle caricature qui se veut gallophobe de ce qu'il condamne comme étant un goût trop prononcé pour le « francesismo »: 
Quand je suis arrivé à Coimbra pour faire l'examen de logique, rhétorique et français, le président de session, professeur du Lycée, [...] a tout de suite demandé aux personnes affectueuses qui s'intéressaient à moi : - A-t-il bien appris sa leçon de français? Et lorsqu'on lui a assuré que je récitais Racine aussi bien que le vieux Talma, le bon vieux bonhomme leva les mains au ciel avec un immense soulagement : - Alors tout va bien! Voilà un homme ! (Queirós 1912 : 389)

Pour lui, comme pour beaucoup d'autres intellectuels portugais du XIX ${ }^{e}$ siècle, le Portugal était devenu l'image même d'« un pays traduit du français en argot », une « copie de la France, imparfaite et grossière » (Queirós $1912: 387$; 398).

\section{Langue, réforme éducative et représentations}

10 L'ancrage sur ces relations culturelles franco-portugaises au XIX ${ }^{\mathrm{e}}$ siècle nous permet d'interroger les liens qui se tissent entre le champ littéraire ou le champ artistique ${ }^{2}$ (Bourdieu 1991) et le milieu éducatif sur la base de deux piliers bien solides, celui d'une lingua franca -- la langue française, langue de culture et de diplomatie -- et celui d'une langue/culture institutionnalisée auprès d'une élite dans le secteur public par les normes de l'Instruction publique. Quels rapports sont alors préconisés entre les savoirs culturels et les savoirs langagiers?

La création du premier programme de français langue étrangère dans le système éducatif portugais et les orientations officielles qui s'en suivirent, au cours de la seconde moitié du XIX ${ }^{e}$ siècle, dénotent un profond changement en ce qui concerne l'approche des langues étrangères et le rôle de la culture. L'approche culturelle constitue alors le noyau de l'apprentissage du FLE, à mi-chemin entre les valeurs de la nation française à travers certains personnages illustres ou certaines habitudes liées à la civilisation quotidienne, d'un côté, et, de l'autre, les principes de la lecture des grands auteurs.

Une analyse comparée de certains livres scolaires (selectas, recueils ou anthologies) adoptés par le système éducatif et des instructions officielles pour les programmes de français au XIX ${ }^{\mathrm{e}}$ siècle nous aidera ici à déterminer les contours d'une nouvelle conception idéologique et pédagogique de l'enseignement de la civilisation-culture française au Portugal, notamment de la culture littéraire.

L'influence des célèbres Leçons françaises de littérature et de morale de Noël et De La Place (1804) reste incontournable car cet ouvrage permet le classement des textes par ce que les auteurs dénomment "morceaux de composition": "narrations", "tableaux", "descriptions", «définitions", "fables», «morale religieuse, ou philosophie pratique », "morceaux lyriques", « discours et morceaux oratoires », "dialogues », «caractères et portraits, et parallèles». Or, certains de ces «morceaux de composition » relèvent de la rhétorique et, quoique voués à la lecture, ils sont essentiellement tournés vers l'imitation et l'art d'écrire. L'élève est initié à des modèles de style français dans le but d'être capable de les réutiliser. Imitation symbolise alors appropriation et, à l'image des Leçons françaises, « les manuels se font alors le véhicule d'une volonté: façonner une conscience nationale, créer une identité commune » (Minerva 2002). Cette conscience et cette identité se trouvent renforcées lors du processus de disciplinarisation de l'enseignement scolarisé. Dans le contexte éducatif, on assigne à l'apprentissage culturel « tout ce qu'un individu doit apprendre pour vivre dans une société particulière » (Rocher 1968 : 113). Les disciplines de langue étrangère 
(langue française, anglaise et/ou allemande, dans le cas portugais) introduisent, par ce contact culturel de l'élève avec les textes écrits, une dichotomie entre ce qui est national et ce qui est étranger, et fortifient par là la notion de système symbolique de toute identité culturelle :

Toute culture peut être considérée comme un ensemble de systèmes symboliques au premier rang desquels se placent le langage, les règles patrimoniales, les rapports économiques, l'art, la science et la religion. Tous ces systèmes visent à exprimer certains aspects de la réalité physique et de la réalité sociale, plus encore, les relations que ces deux types de réalité entretiennent entre eux et que les systèmes symboliques entretiennent les uns avec les autres. (Lévi-Strauss 1950)

La Revista dos lyceus publiait, au mois de septembre 1891, un long article sur la place des selectas et leur nature dans l'enseignement des langues modernes. On y prêchait la nécessité d'introduire quelques éléments nouveaux par rapport aux selectas jugées désuètes du début du siècle. Des extraits de nature littéraire contemporaine -- la nouvelle école réaliste et naturaliste --, devraient y figurer à côté des extraits de nature encyclopédique sur d'autres domaines scientifiques du savoir, à savoir, les mathématiques, l'astronomie, la physique, la chimie, la biologie, la sociologie, entre autres :

Une selecta destinée à l'enseignement d'une langue doit être composée par des extraits dans tous les genres de composition littéraire; exhiber la langue dans toutes les facettes, dans toutes les modalités. Les selectas françaises publiées jusqu'à maintenant accusent dans la majorité des cas le goût classique trop exagéré de leurs auteurs [...] Il y manque des extraits de l'école réaliste ou naturaliste dont les représentants sont, comme on le sait, E. Zola, Flaubert, Goncourt, Daudet, etc. Ces extraits afin de permettre la connaissance de la langue dans tous ses versants, dans toutes ses variantes de la pensée et de l'expression doivent présenter une sorte d'encyclopédie relative à tous les savoirs les plus utiles à l'élève pour son instruction et son éducation. Ils doivent faire référence à tous les faits du monde qui impressionnent le plus les élèves de cette langue.

Ces extraits pourraient ainsi servir non seulement à l'apprentissage de la langue de Voltaire et de Racine, de Chateaubriand et Lamartine, de Victor Hugo et A. Comte, ce grand penseur de la mentalité moderne, mais aussi en tant que livre éducateur de l'esprit des jeunes gens. Ils pourraient présenter d'une façon succincte et claire et dans un style élégant et attrayant les notions primordiales et fondamentales de la mathématique, de l'astronomie, physique, chimie, biologie et sociologie qui constituent la hiérarchie mentale d'A. Comte. (Guimarães 1891 : 190-191)

Trois mois plus tard, Diogo da Fonseca Tavares Leite publiait un article afin de répondre à Correia Guimarães et la polémique était lancée. Il démontrait dans son article qu'il existait déjà dans le marché éditorial portugais des selectas qui répondaient à ce besoin de contemporanéité des textes ainsi qu'à la variété des thématiques dans le domaine scientifique. Il donnait l'exemple de la Selecta franceza para uso dos lyceus de Bernardo Moreira de Sá qui introduisait déjà, au sein de plus de trois centaines d'auteurs cités, deux tiers d'auteurs contemporains et des textes "d'astronomie, physique, chimie, botanique, zoologie, géologie, géographie, histoire, philosophie, économie, ethnologie, etc. " (Leite 1891: 305-306). Mais pour Leite, seul le texte littéraire pouvait préparer l'élève à l'utilisation de cet instrument qu'était la langue française. Seul le contact avec le texte littéraire pouvait le doter de moyens pour la compréhension de la langue et la traduction telle qu'elle était conçue par le système scolaire :

En fin de compte, il ne faut pas oublier que l'étude de la langue française dans les lycées, c'est principalement un moyen, c'est l'acquisition d'un instrument; par 
conséquent, l'étude du français doit être essentiellement l'étude de l'idiome français. De là vient la nécessité impérieuse d'assigner un caractère extrêmement littéraire à toute selecta française. On peut affirmer avec assurance que, si un élève de français étudiait dans une selecta composée d'extraits purement scientifiques, il serait totalement incapable de traduire une page de n'importe quelle œuvre littéraire, ou de comprendre la moitié d'une colonne d'un journal français. (Leite 1891 : 305)

Que s'était-il passé pendant le demi-siècle qui précède ces articles publiés dans l'une des revues d'instruction de l'enseignement secondaire la plus reconnue dans le pays?

Après la loi de la création des lycées en 1836, il a fallu attendre plus de vingt ans pour connaître le premier texte réglementaire sur la fixation des livres d'enseignement dans les cours et établissements publics. En effet, le 31 janvier 1860 était publié le « Regulamento para a approvação e adopção das obras destinadas ao ensino » afin de distinguer les livres adoptés -- ceux qui étaient admis par le gouvernement pour «servir de texte dans tous les cours et établissements publics »-- des livres approuvés, c'est-à-dire «tous ceux qui, ne contrariant en rien la religion, la morale et la constitution ", pouvaient contribuer à la civilisation du Portugal, une fois jugé leur " mérite littéraire ou scientifique » (Regulamento $1860: 29$ ).

Voyons comment apparaissent dans les listes de livres adoptés et approuvés les selectas, recueils ou anthologies de textes composés à partir d'extraits d'auteurs de la culture française.

La première "Relação dos livros approvados e adoptados pelo conselho geral de instrucção publica, para poderem ser lidos nas escolas publicas de instrucção primaria e secundaria, na conformidade do decreto de 31 de janeiro de 1860 » est diffusée le 28 septembre 1861. Or, dans cette liste, sont indiquées uniquement deux grammaires de français : la $3^{\mathrm{e}}$ édition de la Grammaire française de Mauperrin (livre approuvé) et la Grammatica de lingua franceza de José Roquete (livre adopté). Deux ans plus tard, en 1863, la situation se répète : seuls les Elementos de grammatica franceza de Lhomond, traduits par Miguel de Bourdiec et la Grammatica franceza theorica e pratica de Emilio Achilles Monteverde sont approuvés. Bien que la Selecta franceza ou trechos extrahidos dos melhores auctores francezes de José Roquete n'ait pas été intégrée dans cette résolution du Ministère, nous savons aujourd'hui qu'elle fut très utilisée dans l'enseignement du français au cours du XIXe siècle. Il aura fallu attendre une résolution de la fin du siècle, signée par le ministre José Luciano de Castro, le 21 octobre 1897, pour qu'une nouvelle édition de la Selecta de Roquete, remaniée, revue et augmentée par Léopold Marcon, soit approuvée pour cinq ans. Mais, face au développement du marché éditorial et aux nouvelles exigences pédagogiques, certains professeurs de langues vivantes lancent dans le marché national plusieurs anthologies. Tel est le cas de Jacob Bensabat, qui a vu approuvée sa selecta Lectures morales et morceaux choisis des classiques français en 1881, et Bernardo Moreira de Sá, qui a vu approuvée sa Selecta francesa l'année suivante.

Les selectas de ces deux auteurs naissent surtout en réaction contre les Leçons françaises de Noël et De la Place et celle qui avaient été créées à leur image, la Selecta franceza de Roquete. Cette réaction a elle-même des fondements pédagogiques qui marquent un tournant dans l'approche de la culture française. Celle-ci devient le noyau de l'apprentissage du français dans les lycées puisque la lecture du texte littéraire ne sert plus uniquement les fins linguistiques et grammaticales en vue de la traduction, mais sert de tremplin vers la connaissance de la civilisation française, y compris par le 
contact avec des auteurs contemporains et des thématiques à caractère encyclopédique et moderne.

$21 \mathrm{Si}$, pendant les premières décennies de la deuxième moitié du siècle, ou du moins, jusqu'au début des années 1870 (au moment de la parution du premier programme de français, en 1872), on préfère la loi de la transmutation des textes des auteurs français (que l'on laisse dans l'anonymat), dans les dernières décennies du siècle (surtout, à partir des années 1880), on préfère donner des morceaux choisis accompagnés du nom d'auteur dans une volonté affichée de culte des grands auteurs. Ces deux tendances ne sont pas fortuites. Elles véhiculent deux approches différenciées de l'approche du fait culturel dans les manuels d'enseignement du français de l'époque: une première tendance avec une forte incidence pédagogique sur la langue et son exploitation linguistique ou grammaticale (l'apprentissage de la prononciation, de la morphologie ou de la syntaxe); une deuxième tendance qui valorise l'approche du fait littéraire et culturel. L'exploitation de cette dimension littéraire et culturelle de l'apprentissage de la langue se concrétise par la valorisation du culte des grands auteurs, voie ouverte vers la formation morale, l'esprit cultivé et civilisé.

\section{Conclusions}

À la fin du XIX ${ }^{\mathrm{e}}$ siècle, la Revista dos lyceus faisait connaître à ses lecteurs, sous le titre "Les progrès de la langue française ", un texte qui avait été publié dans Le Petit Journal à Paris sous le pseudonyme de Thomas Grimm ${ }^{3}$ et qui faisait l'apologie du prestige du français en reprenant quelques statistiques sur la diffusion des langues en Europe et dans le monde :

La langue française fait, aux dépens de la langue allemande, de grands progrès ; [...] Le français n'est pas seulement en progrès sur l'allemand, il l'est encore sur l'italien et le romanche. [...] De toutes les langues européennes, quelle est la plus répandue dans le monde entier? C'est l'anglais, diraient des Anglais. C'est le russe, répondraient des Russes, les uns et les autres auraient raison. [...] L'espagnol, resté langue maternelle des Américains du Sud (pas tous; au Brésil, on se sert du portugais), est parlé par 48 millions d'âmes. (Grimm 1891)

23 À un moment où on discutait la place de l'anglais et, surtout de l'allemand, à côté de la langue étrangère dominante, le français, dans le secteur de l'éducation portugaise, il n'était pas étonnant de voir apparaître un tel article propagandiste. Mais, ce qui a attiré surtout notre attention dans cet article c'est sa réflexion sur les représentations des langues en Europe, notamment du français, vu non seulement comme langue de la diplomatie mais surtout comme "idiome de civilisation", voie ouverte vers la formation des « esprits vraiment cultivés »:

Voici donc les quatre langues qui ont le plus d'adhérents, mais n'oublions pas que partout les esprits vraiment cultivés, s'ils n'ont pas le français comme langue maternelle, savent cependant s'exprimer en français.

Le Petit Journal a déjà dit quel avenir était réservé à notre langue dans ses colonies et dans quelques autres pays, en Égypte par exemple. Pour Villemain «la langue française est et doit rester l'idiome de la civilisation ». L'Europe l'a si bien compris qu'elle a conservé la langue française comme langue de la diplomatie, cette glorification du français date déjà du seizième siècle ; c'est l'empereur CharlesQuint, notre implacable ennemi, qui l'a déclaré langue d'État. Et il disait que, s'il voulait parler à Dieu, il parlerait espagnol (il était Espagnol !) ; que s'il voulait parler 
à des hommes, il parlerait français ; à des femmes, il parlerait italien ; à son cheval, il parlerait allemand.

Ce n'est guère flatteur pour l'idiome germanique, mais ce qui l'est encore moins, c'est le fait que signalent les statistiques, c'est le progrès de la langue française. (Grimm 1891) été privilégiée au Portugal dans le système secondaire pendant tout le XIX ${ }^{\mathrm{e}}$ siècle. Le culte rendu aux Belles Lettres contribue ainsi à l'ennoblissement et au prestige de la langue française.

L'éloignement de la méthode traditionnelle "grammaire-traduction " coïncide alors avec une nouvelle mission assignée à la langue, une mission civilisatrice dans laquelle la langue est porteuse de valeurs et d'idées au sein de la réalisation d'un «objectif social de référence » (Puren 2014).

Certes, on est encore bien loin de l'approche interculturelle ${ }^{4}$ introduite par l'approche communicative et l'approche actionnelle au $\mathrm{XX}^{\mathrm{e}}$ siècle et de la prise en compte des «dissonances culturelles et de la distinction de soi » (Lahire 2004). Au XIX ${ }^{\mathrm{e}}$ siècle, le contact avec la culture de l'Autre servait essentiellement encore un objectif de nature rhétorique comme nous l'avons vu avec l'un des modèles qui a le plus circulé en Europe, les Leçons de Noël et De la Place. Le travail en classe motivé par le contact avec la culture étrangère servait le propos de la composante métaculturelle où, sous la forme de modèle à imiter, l'élève devait surtout mobiliser ses connaissances culturelles.

\section{BIBLIOGRAPHIE}

(1860). « Regulamento para a aprovação e adopção das obras destinadas ao ensino », Diário do Governo, 31 janvier, 29-32.

BENSABAT, Jacob (1881). Lectures morales et morceaux choisis des classiques français/ Nova selecta franceza ou trechos extrahidos dos melhores clássicos francezes em prosa e verso para o estudo da língua franceza, em conformidade com os novos programmas dos lyceus do reino... Porto : Livraria Portuense Clavel \& $\mathrm{C}^{\mathrm{a}}$.

BOISTE, Pierre-Claude-Victor (1803 [1800]). Dictionnaire universel de la langue françoise avec le latin, et, manuel d'orthographe et de néologie. Paris : Librairie Boiste. En ligne :

[http://gallica.bnf.fr/ark:/12148/bpt6k5849452x/f8.image] (19 juin 2018).

BOURDIEU, Pierre (1971). « Le marché des biens symboliques ». L'Année sociologique, troisième série, Vol. 22, 49-126.

BOURDIEU, Pierre (1991). « Le champ littéraire », Actes de la Recherche en Sciences Sociales, 89, 3-46. En ligne :

[https://www.persee.fr/doc/arss_0335-5322_1991_num_89_1_2986]

(19 juin 2018).

Documents pour l'histoire du français langue étrangère ou seconde, 60-61 | 2018 
DÜWELL, Henning (1996). «L'universalité de la langue française au $18^{\mathrm{e}}$ siècle vue par un Allemand: Johann Christoph Schwab », Documents pour l'histoire du français langue étrangère ou seconde, 18, 41-50.

ESCOFFIER, Henri (GRIMM, Thomas) (1891). Le petit journal. 17 octobre. En ligne : [https:// gallica.bnf.fr/ark:/12148/bpt6k611017q.r=

17\%20octobre\%201891?rk=42918;4] (19 juin 2018).

GUIMARÃES, José Correia P (1891). «O ensino das línguas modernas. As selectas », Revista dos lyceus, 4-5, septembre, 190-192.

HAGÈGE, Claude (2006). Combat pour le français. Au nom de la diversité des langues et des cultures. Paris : Odile Jacob.

KLINKENBERG, Jean-Marie (2008). «L'héritage du passé : aux origines de l'expansion du français ». In Jacques Maurais et al., L'avenir du français. Paris : Éditions des Archives Contemporaines, 9-13.

LAHIRE, Bernard (2004). La culture des individus : dissonances culturelles et distinction de soi. Paris : La Découverte.

LEITE, Diogo da Fonseca Tavares (1891). « Obervações ao artigo O ensino das línguas modernas. As selectas », Revista dos lyceus, 7, décembre, 304-306.

LÉVI-STRAUSS, Claude (1950). « Introduction à l'œuvre de Marcel Mauss ». In Marcel Mauss, Sociologie et anthropologie. Paris : P.U.F. En ligne : [http://palimpsestes.fr/textes_philo/ levi_strauss/

surmauss.pdf] (19 juin 2018).

MINERVA, Nadia (2002). « France/Italie : une identité d'emprunt ou une identité en partage ?", Documents pour l'histoire du français langue étrangère ou seconde, 28, 119-134.

NOËL, François-Joseph-Michel \& DE LA PLACE, François de (1820 [1804]). Leçons françaises de littérature et de morale, ou Recueil, en prose, en vers des plus beaux morceaux de notre langue dans la littérature des deux derniers siècles. Paris : Le Normant. En ligne : t.1 : [https:// gallica.bnf.fr/ark:/12148/bpt6k64728096/f9.image] et t.2 : [https://gallica.bnf.fr/ark:/12148/ bpt6k6471785x/f9.image] (19 juin 2018).

PUREN, Christian (2014). « La compétence culturelle et ses différentes composantes dans la mise en œuvre de la perspective actionnelle. Une nouvelle problématique didactique ", Intercâmbio, $2^{\text {a }}$ série, vol. 7, 21-38. En ligne : [http://ler.letras.up.pt/site/default.aspx?qry= id05id1184id2686\&sum=sim] (19 juin 2018).

QUEIRós, Eça de (1912). «O Francesismo ». In Últimas páginas. Manuscritos Inéditos. Porto : Lello \& Irmão Editores.

RIVAROL, Antoine (1784). De l'Universalité de la langue française ; Discours qui a remporté le Prix de l'Académie de Berlin. Berlin/Paris : Bailly/Dessenne. En ligne : [http://gallica.bnf.fr/ark:/

12148/bpt6k81622t/f3.image] (19 juin 2018).

ROCHER, Guy (1968). Introduction à la sociologie générale. 1. L'action sociale. Montréal : Ed. HMH. ROQUETE, José Inácio (1862). Selecta franceza ou trechos extrahidos dos melhores autores francezes em prosa e em verso, para uso dos que aprendem a lingua franceza, enriquecida de noticias biographicas, e notas grammaticaes e philologicas. nova ed. aum. p/ Léopold Marcou, Paris-Lisboa : V. J.-P. Aillaud, Guillard \& C. . 
SÁ, Bernardo V. Moreira de (1884). Selecta franceza para uso dos lyceus, compilada, annotada e com referencias numerosas á grammatica franceza dos snrs. J. Eduard Von Hafe e A. Epiphanio da Silva Dias. $3^{a}$ ed., melhorada e acrescentada com um vocabulário de 1500 palavras. Porto : Livraria Universal de Magalhães \& Moniz eds.

VILLEMAIN, Abel-François (1835). « Préface ». Dictionnaire de l'Académie Française, tome 1, $6^{\mathrm{e}}$ édition, Paris, Imprimerie et Librairie Firmin Didot Frères. En ligne : [https://gallica.bnf.fr/ark:/ 12148/bpt6k50407h/f6.image].

\section{NOTES}

1. Ajoutons à cela que le discours de Schwab annonce déjà un peu plus loin une vision prémonitoire de la projection de l'anglais: "Ceci ne doit s'entendre que de l'Europe, car la langue anglaise peut, en suivant le rapport des accroissements de l'Amérique septentrionale, y acquérir un empire prodigieux » (Düwell 1996 : 45).

2. Dans un $n^{\circ}$ de la revue Actes de la Recherche en Sciences Sociales entièrement consacré au champ littéraire, Pierre Bourdieu consacre plus d'une quarantaine de pages au traitement de cette notion qui lui est chère avec la réédition d'un texte qu'il avait écrit en 1982 et qu'il avait présenté l'année suivante dans un séminaire à Bad Homburg. Pour lui, le champ littéraire, artistique, etc. " est un champ de forces agissant sur tous ceux qui y entrent, et de manière différentielle selon la position qu'ils y occupent (soit, pour prendre des points très éloignés, celle d'auteur de pièces à succès ou celle de poète d'avant-garde), en même temps qu'un champ de luttes de concurrence qui tendent à conserver ou à transformer ce champ de forces » (Bourdieu 1991 : 4-5).

3. Thomas Grimm était, en effet, le pseudonyme collectif utilisé par Henri Escoffier, rédacteur en chef du Petit Journal (depuis 1873), et par ses collaborateurs dans leur chronique quotidienne dans ce journal parisien.

4. Nous rappelons ici la position de Christian Puren qui, en 2014, systématise cette approche pédagogique contemporaine en ces termes : «Pour qu'il y ait contact interculturel, il faut (comme aurait dit Monsieur de La Palice...) qu'il y ait des cultures différentes, donc du multiculturel; et pour que ce contact se maintienne dans la durée, il faut qu'il y ait pour cela un intérêt commun renvoyant forcément à un minimum de valeurs partagées telles que l'ouverture à l'autre et l'enrichissement par la découverte de l'autre, c'est-à-dire à du transculturel. - On ne peut apprécier les différences (dans les deux sens de ce verbe : les reconnaitre et les valoriser), objectif que se donne l'éducation à l'interculturel, que si l'on reconnaît préalablement chez l'autre un être humain comme soi-même - ce qui relève du transculturel - et que si l'on reconnaît à cet autre le droit à maintenir des différences par rapport à sa propre culture - ce qui relève du multiculturel » (Puren 2014 : 25).

\section{RÉSUMÉS}

Nous proposons ici une réflexion sur les différentes approches de la culture dans l'enseignement $\mathrm{du}$ français langue étrangère au Portugal au XIXe siècle. Les relations culturelles francoportugaises s'intensifient à l'époque grâce à certains agents culturels et, entre gallomanie et gallophobie, s'édifient les deux piliers bien solides de l'enseignement des langues modernes, celui 
d'une lingua franca _- la langue française, langue de culture et de diplomatie _- et celui d'une langue/culture institutionnalisée auprès d'une élite dans le secteur public par les normes de l'Instruction publique. Une analyse comparée de certains livres scolaires (selectas ou anthologies) adoptés par le système éducatif et des instructions officielles pour les programmes de français nous aide à déterminer les contours d'une nouvelle conception idéologique et pédagogique de l'enseignement de la civilisation-culture, y compris de la culture littéraire. Quels rapports s'établissent alors entre les savoirs culturels et la transmutation des savoirs langagiers et pédagogisés?

We propose here a reflection on the different approaches of culture in the teaching of French as a foreign language in Portugal in the nineteenth century. Franco-Portuguese cultural relations intensified at the time thanks to certain cultural agents and, between gallomania and gallophobia, the two solid pillars of the teaching of modern languages were built, that of a lingua franca _- the French language, language of culture and diplomacy _- and that of a language/ culture institutionalized for an elite in the public sector by the guidelines of Public Instruction. A comparative analysis of selected school books (selectas or anthologies) adopted by the education system and official instructions for French programs helps us to determine the contours of a new ideological and pedagogical conception of the teaching of civilization-culture, including literary culture. What relationships are then established between cultural knowledge and the transmutation of language and pedagogical knowledge?

\section{INDEX}

Mots-clés : Portugal, XIXe siècle, culture française, enseignement FLE

Keywords : Portugal, 19th century, French culture, teaching French

\section{AUTEUR}

\section{ANA CLARA SANTOS}

Université d'Algarve -avsantos@ualg.pt 